\title{
Liquid Chromatography-tandem Mass Spectrometry (LC-MS/MS) Assay for Simultaneous Measurement of Salivary Testosterone and Cortisol in Healthy Men for Utilization in the Diagnosis of Late-onset Hypogonadism in Males
}

\author{
FutOSHI MATSUI*, EITETSU KOH*, KeNROU YAMAMOTO*, KAZUHIRO SUGIMOTO*, Ho-Su SIN*, \\ YuJI MAEDA*, SEIJIRO HONMA** AND MiKIO NAMIKI* \\ * Department of Integrative Cancer Therapy and Urology, Kanazawa University Graduate School of Medical Science, Kanazawa, \\ Ishikawa 920-8641, Japan \\ **ASKA Medical Co. Ltd., Kawasaki, Kanagawa 213-8522, Japan
}

\begin{abstract}
It is well known that late-onset hypogonadism in males can cause a variety of symptoms, and the differential diagnosis is relatively difficult, including psychological disorders, stress, and mood disturbances. The level of serum cortisol can be measured to reflect a patient's level of stress. Salivary hormones facilitate the evaluation of physiological hormonal actions based on free hormone assay. For the simultaneous measurement of testosterone and cortisol levels in saliva, we validate a sensitive liquid chromatography-tandem mass spectrometry (LC-MS/MS) assay. Concerning accuracy and precision, the lower limit of quantification of salivary testosterone and cortisol were established as 5 and $10 \mathrm{pg} / \mathrm{mL}$, respectively. Testosterone and cortisol in saliva is stable for 2 days, 14 days, and 28 days at room temperature, refrigeration and frozen, respectively. Freezing and thawing for 3 cycles and stimulation of salivation with gum chewing do not alter the measured values of testosterone and cortisol. Total, bioavailable, and free serum testosterone showed slight diurnal changes, but total and bioavailable serum cortisol showed marked diurnal changes. Salivary testosterone levels negatively correlate with age, regardless of the time of saliva collection $(\mathrm{r}=0.64, p<0.05)$. However, there is no relationship between salivary cortisol and age $(r=0033, p>0.05)$. LC-MS/MS allows rapid, simultaneous, sensitive, and accurate quantification of testosterone and cortisol in saliva for the diagnosis late-onset hypogonadism or other hormone related disease.
\end{abstract}

Key words: Salivary testosterone, Cortisol, Late-onset hypogonadism, Stress, LC-MS/MS

(Endocrine Journal 56: 1083-1093, 2009)

SALIVA contains many hormones and can be used to detect the presence of drugs and antibodies. The salivary concentrations of steroid hormones are approximately 1 to $5 \%$ of their serum concentrations; the percentage in comparison to serum concentrations depends upon the type of hormone. Cortisol (F) shows the highest percentage (approximately $5 \%$ ), followed by testosterone ( $\mathrm{T}$; approximately $2 \%$ ); estradiol has the lowest percentage ( $1 \%$ or less) in healthy adults $[1$,

Received Jul. 2, 2009; Accepted Aug. 25, 2009 as K09E-186 Released online in J-STAGE as advance publication Sep. 5, 2009

Correspondence to: Eitetsu KOH, M.D., Ph.D., Department of Integrative Cancer Therapy and Urology, Kanazawa University Graduate School of Medical Science, 13-1 Takara-machi, Kanazawa, Ishikawa 920-8641, Japan.

E-mail: kohei@med.kanazawa-u.ac.jp
2]. The differences may be associated with molecular structure variations in water solubility, differences in binding affinity to sex hormone-binding globulin (SHBG) in serum, or the serum free hormone ratio [3]. However, the mechanism by which hormones are secreted in saliva via blood remains to be clarified. Autoradiograms showed free $\mathrm{T}$ was secreted in saliva without binding to SHBG [4]. Recent studies reported $\mathrm{T}$ and $\mathrm{F}$ in saliva were useful for evaluating bioavailability and accurately reflected serum hormone activity $[1,3,5-8]$. Some studies indicated the measurement of salivary hormone levels facilitated the evaluation of precise physiologic actions based on free hormone activity, which could not be confirmed based on total blood hormone levels $[1,3,6,9]$. Therefore, salivary hormone measurements have re- 
ceived much interest.

To measure trace hormones in saliva, radioimmunoassay (RIA) and enzyme immunoassay (EIA) techniques have been employed, as reported for serum hormone measurements [10-12]. However, the values markedly differ compared to those determined by liquid chromatography-tandem mass spectrometry (LCMS/MS) [13, 14]. Therefore, we determined salivary hormone levels using a standard method for steroid hormone micro-measurement, LC-MS/MS. Generally, the sensitivity of this method is approximately 10 to 100 times higher than that of RIA, with a high degree of accuracy. Furthermore, the simultaneous quantification of several steroid hormones facilitates an accurate differential diagnosis.

Salivary testosterone is not only utilized to evaluate androgen related conditions, but also in research on emotion and sports medicine [15-17]. Some investigators proposed salivary testosterone level as a criterion of late-onset hypogonadism $(\mathrm{LOH})$ in males $[7,18]$. On the other hand, salivary cortisol may be useful for evaluation of the degree of stress and in the diagnosis of hormone related diseases, such as Cushing's disease [19-22]. Males suspected of having $\mathrm{LOH}$ in males show various clinical symptoms including reduced concentration ability, abulia, hypochondriasis, mood disturbances, and passivity. It is important to accurately differentiate $\mathrm{LOH}$ from stress and depression disorders [23].

In this study, we established a method for simultaneous measurement of salivary $\mathrm{T}$ and $\mathrm{F}$ using LC-MS/ MS to confirm absolute ranges of $\mathrm{T}$ and $\mathrm{F}$ levels. In addition, we investigated saliva collection methods, storage conditions, and diurnal changes in these hormones in healthy adults for the purpose of aiding in the differential diagnosis of stress and depression disorders from $\mathrm{LOH}$ in males.

\section{Materials and Methods}

\section{Reagents}

$\mathrm{T}$ and $\mathrm{F}$ were purchased from Sigma Co., Ltd (St. Louis, MO, USA). Internal standard (IS) substances, testosterone- $\mathrm{d}_{3}$ (T-d3) (testosterone-16,16,17- ${ }^{2} \mathrm{H}_{3}$, purity: $98.5 \%$ ) and cortisol- $\mathrm{d}_{4}(\mathrm{~F}-\mathrm{d} 4)$ (cortisol-9,11,12,12${ }^{2} \mathrm{H}_{3}$, purity: $98.5 \%$ ), were purchased from $\mathrm{D} / \mathrm{N} / \mathrm{P}$ (Quebec, Canada). Bond Elut C18 (for $3 \mathrm{~mL}, 200 \mathrm{mg}$ filling) for solid-phase extraction was purchased from Varian Inc (CA, USA). We used liquid chromatography mass spectrometry (LC-MS) grade methanol and acetonitrile. Hormone-free saliva (zero saliva) and serum (zero serum) were prepared by adding $8 \mathrm{~g}$ of activated carbon and $0.5 \mathrm{~g}$ of dextran to $100 \mathrm{~mL}$ of saliva and serum, agitating these samples on ice overnight, and then centrifuging at $3,000 \mathrm{x}$. The obtained supernatants were again centrifuged at 8,000 x g for $2 \mathrm{hr}$ to produce hormone free saliva or serum.

\section{Participants and specimen collection}

This study was approved by the Ethics Committee of Kanazawa University Hospital and informed consent was obtained from all participants. Healthy volunteer males aged 25 to 65 years were classified into four age groups: 5 subjects 21 to 30 years old, 6 subjects 31-40 years old, 6 subjects 41-60 years old, and 5 subjects greater than 61 years old. These healthy control subjects who had no history of illness and were not taking medications were enrolled in this study. For saliva collection, the mouth was rinsed with water and then saliva was directly placed in a Bakelite test tube $(15 \mathrm{~mL})$ and stored at $-70^{\circ} \mathrm{C}$ until analysis. Blood samples were centrifuged to isolate serum. Serum samples were stored at $-70^{\circ} \mathrm{C}$ until analysis.

\section{LC-MS devices and measurement conditions}

We employed an API 4000 electrospray ionization (ESI) mass spectrometer (Applied Biosystems/ MDS SCIEX, Foster City, CA, USA). For high-performance liquid chromatography (HPLC), we used an Agilent 1100 device (Agilent Technology, CA,USA), HTC PAL autosampler (CTC Analytics, Zwingen, Switserland), and Cadenza CD-C18 column (3 $\mu \mathrm{m}$, $3 \times 150 \mathrm{~mm}$ ) (Imatake, Kyoto, Japan). For MS measurements, we employed the positive-ion mode and the injection volume was $10 \mu \mathrm{L}$. The ion spray voltage and ion source temperature were established as $5,000 \mathrm{~V}$ and $500^{\circ} \mathrm{C}$, respectively.

Extraction and purification of $T$ and $F$ in saliva and serum

Serum $(100 \mu \mathrm{L})$ was diluted with purified water to prepare a volume of $1 \mathrm{~mL}$. Methanol IS solution (T-d3, $1 \mathrm{ng} ; \mathrm{F}-\mathrm{d} 4,2 \mathrm{ng} / 100 \mu \mathrm{L}$ ) was added to the saliva (1 
$\mathrm{mL}$ ) and diluted serum. These samples were mixed with $4 \mathrm{~mL}$ of ethyl acetate, agitated for 10 minutes, and centrifuged at 3,000 rpm for 10 minutes. After the water layer was frozen, the ethyl acetate layer was isolated. The solution was evaporated using a centrifugation evaporator. The extract was dissolved in 100 $\mu \mathrm{L}$ of $70 \%$ acetonitrile solution, and $10 \mu \mathrm{L}$ of this solution was injected into the LC-MS/MS device.

\section{Validation for the simultaneous quantification of $T$ and} $F$ in saliva and serum

The methods used for LC-MS/MS device were essentially similar to those described previously $[9,24]$. Specificity: Zero saliva $(1 \mathrm{~mL})$ and serum $(0.1 \mathrm{~mL})$ from healthy males $(1 \mathrm{~mL})$ were extracted, as described above. Subsequently, a portion of these extracts was analyzed via LC-MS/MS. T, T-d3, F and F-d4 were determined using selective reaction monitoring (SRM) of the following transitions $(\mathrm{m} / \mathrm{z})$ 289.3 - 97.3, 292.3 - 97.3, 363.3 - 327.1 and 367.3 - 331.3 respectively. Recovery rate: $\mathrm{T}$ or F (100 pg) was added to zero serum, and then extracted/purified, as described above. LC-MS/MS was performed. Reproducibility test: Using zero serum $(\mathrm{n}=5)$ or saliva $(n=5)$, an intraday reproducibility test was conducted within the concentration ranges of $\mathrm{T}$ and $\mathrm{F}$ shown in the Results section. Interday reproducibility $(n=15)$ was investigated 3 times on different days at the same concentrations as employed in the simultaneous reproducibility test.

\section{Storage stability of saliva}

Using a portion of saliva collected from healthy males ( $\mathrm{n}=12$, approximately $10 \mathrm{~mL}$ ), we immediately analyzed $\mathrm{T}$ and $\mathrm{F}$ and regarded measurements as initial values. Subsequently, the residual saliva was stored at room temperature $\left(25^{\circ} \mathrm{C}\right)$, in a refrigerator $(8$ to $\left.12^{\circ} \mathrm{C}\right)$, or in a freezer $\left(-65\right.$ to $\left.-72^{\circ} \mathrm{C}\right)$ for 1 to 4 weeks. Individual samples were analyzed for serial changes in the $\mathrm{T}$ and $\mathrm{F}$ levels.

\section{Freezing and thawing of serum and saliva}

We measured the levels of $\mathrm{T}$ and $\mathrm{F}$ in saliva and serum collected from healthy males $(n=12)$, and regarded the values as initial values. Subsequently, the same samples were frozen and thawed 3 times, and then the
$\mathrm{T}$ and $\mathrm{F}$ levels were additionally measured.

Diurnal changes in the serum or saliva levels of $T$ and $F$

Changes within 24 hours: Saliva and serum samples were collected for different age groups from healthy males $(\mathrm{n}=22)$ at 6:00, 9:00, 14:00, 17:00, and 22:00. Changes over 4 days: Saliva was collected from healthy males $(\mathrm{n}=5)$ at 9:00, 13:00, 17:00, and 21:00 for 4 consecutive days.

\section{Quantification of bioavailable $T$ and $F$ in serum}

Measurement of bioavailable T and F: SHBG was aggregated by adding $5 \%$ concanabalin $\mathrm{A}(50 \mu \mathrm{L})$ to serum $(0.1 \mathrm{~mL})$, and then removed by centrifugation [25]. After free and albumin-binding, $\mathrm{T}$ and $\mathrm{F}$ in the supernatant fraction were extracted with ethyl acetate. The $\mathrm{T}$ and $\mathrm{F}$ levels were determined using LC-MS/MS.

\section{Statistical analysis}

Data were analyzed using the Statistical Package for the Social Sciences statistical software version 11.0 (SPSS, Chicago, IL, USA). Associations between variables were examined using Pearson's product moment correlation coefficient. A $P$ value of $<0.05$ was considered statistically significant.

\section{Results}

\section{Quantification validation}

The calibration curves were constructed using IS $\mathrm{T}-\mathrm{d} 3$. The regression lines obtained were linear with a correlation coefficient of 0.999 within the range of 5-1000 pg for $\mathrm{T}$ and 10-1000 pg for $\mathrm{F}$. In the validation results, the detection rates of $\mathrm{T}$ and $\mathrm{F}$ in the measurement areas in purified water, zero saliva, and zero serum were $15 \%$ or less of those of $\mathrm{T}$ at $5 \mathrm{pg}$ and $\mathrm{F}$ at $10 \mathrm{pg}$. The respective ion intensity was $4 \%$ or less of that of $\mathrm{T}-\mathrm{d}_{3}$ at $1,000 \mathrm{pg}$ or F-d4 at 1,000pg. There was no influence on the quantification of $\mathrm{T}$ or $\mathrm{F}$. Concerning precision and accuracy of quantification, these two parameters were both within $20 \%$ or less. The lower limit quantities of saliva $\mathrm{T}$ and $\mathrm{F}$ were established as 5 and $10 \mathrm{pg}$, respectively (Table 1). This method was highly reproducible, accurate, and sensitive. 
Table 1. Accuracy and precision of the measurement of testosterone and cortisol

\begin{tabular}{|c|c|c|c|c|c|c|c|c|}
\hline \multicolumn{5}{|c|}{ Inter-assay ( $\mathrm{n}=15,3$ days) } & \multicolumn{4}{|c|}{ Intra-assay $(n=5)$} \\
\hline \multirow{2}{*}{ Compound } & Added & Determination & Accuracy & Precision & Concentration & Determination & Accuracy & Precision \\
\hline & (pg) & (pg) & $(\%)$ & $(\%)$ & $(\mathrm{pg} / \mathrm{mL})$ & $(\mathrm{pg} / \mathrm{mL})$ & $(\%)$ & $(\%)$ \\
\hline \multirow[t]{4}{*}{ Testosterone } & 5 & $5.36 \pm 0.02$ & 7.2 & 0.3 & 5 & $4.78 \pm 0.3$ & -4.5 & 7.3 \\
\hline & 500 & $501.05 \pm 8.86$ & 0.2 & 1.8 & 10 & $9.15 \pm 0.6$ & -8.5 & 6.8 \\
\hline & 1000 & $999.07 \pm 28.76$ & -0.1 & 2.9 & 500 & $497.02 \pm 5.9$ & -0.6 & 1.2 \\
\hline & & & & & 1000 & $982.48 \pm 18.2$ & -1.8 & 1.9 \\
\hline \multirow[t]{4}{*}{ Cortisol } & 20 & $20.86 \pm 1.21$ & 4.3 & 5.8 & 10 & $11.64 \pm 1.8$ & 16.4 & 15.8 \\
\hline & 1000 & $991.71 \pm 16.76$ & -0.8 & 1.7 & 20 & $23.10 \pm 3.7$ & 15.5 & 16.0 \\
\hline & 10000 & $9835.06 \pm 133.1$ & -1.6 & 1.4 & 1000 & $1034.75 \pm 27.8$ & 3.5 & 2.7 \\
\hline & & & & & 1000 & $10167.5 \pm 238$ & 1.7 & 2.3 \\
\hline
\end{tabular}

\section{Storage stability of saliva}

The results regarding the stability of $\mathrm{T}$ and $\mathrm{F}$ in saliva samples $(\mathrm{n}=12)$ stored at room temperature, in a refrigerator, or in a freezer are indicated in Fig. 1a and $1 \mathrm{~b}$. When saliva was placed at room temperature for 2 days, the stability of $\mathrm{T}$ was $80 \%$ or less in 2 samples. When saliva was further stored in this state, the stability was reduced. When saliva was stored in a refrigerator for 7 days, the stability of T was $80 \%$ or less in 2 samples. When saliva was stored in a freezer for 28 days, all samples were stable (Fig. 1a); suggesting that

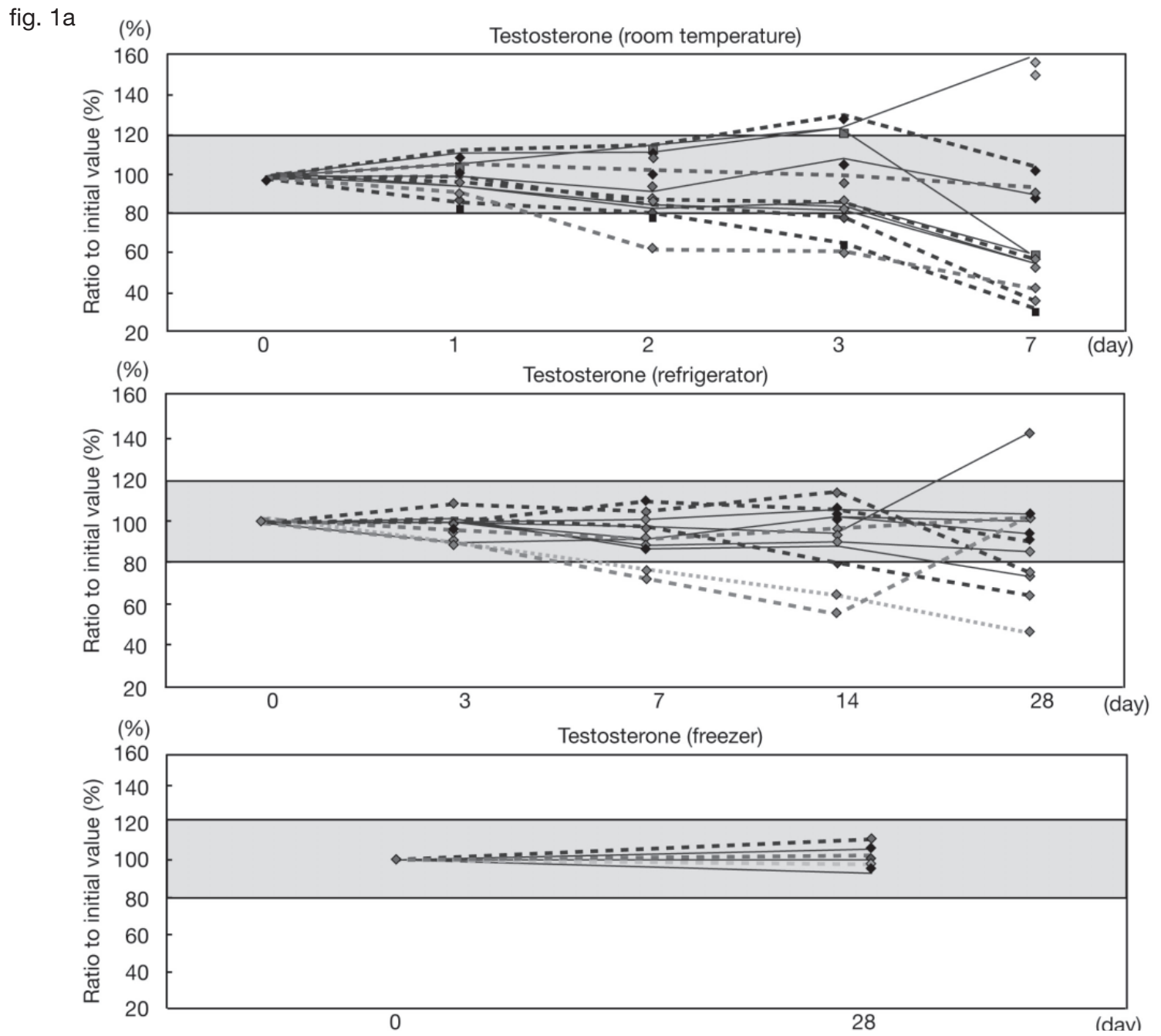


fig. $1 b$
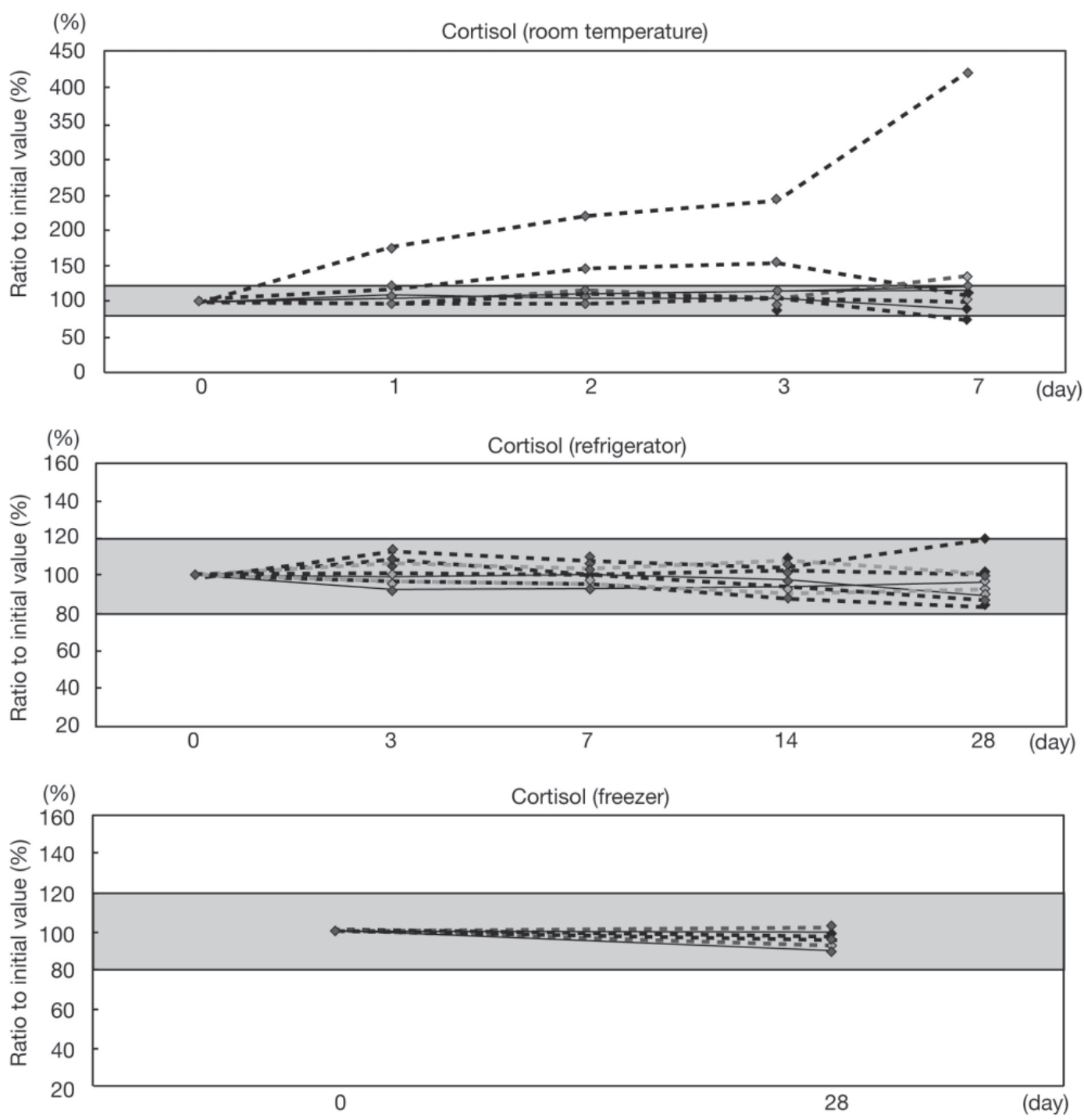

Fig. 1. The stability of (a) testosterone and (b) cortisol in saliva. Each panel shows the measured hormone of each sample in response to storage conditions at room temperature, in a refrigerator, and in a freezer.

$\mathrm{T}$ is stable in frozen saliva.

Concerning F, when saliva was placed at room temperature for 2 days, 2 samples showed a variation of $20 \%$ or more of the initial value. When saliva was further stored in this state, the variation increased. However, when saliva was stored in a refrigerator for 14 days or in a freezer for 28 days, the stability of $\mathrm{F}$ was $90 \%$ or more (Fig. 1b). Under these storage conditions, saliva $\mathrm{F}$ was stable. When an equivalent volume of ethanol was added to saliva, and placed at room temperature for 5 days, the rates of change in the $\mathrm{T}$ and $\mathrm{F}$ levels were $15 \%$ or less of the initial values.

\section{Freezing and thawing}

When serum and saliva were run after being frozen and thawed 3 times, the stability of $\mathrm{T}$ and $\mathrm{F}$, in comparison with the initial values, was $95.7 \%$.

\section{Stimulation of saliva secretion and the saliva levels of T and F}

In healthy males aged 20 to 60 years $(n=12)$, we examined changes in the salivary levels of $\mathrm{T}$ and $\mathrm{F}$ when saliva secretion was stimulated with gum chewing and in the absence of stimulation using the cross- 
Table 2. Salivary testosterone and cortisol levels in response to gum

\begin{tabular}{|c|c|c|c|c|c|c|}
\hline \multirow[t]{2}{*}{ No. } & \multirow[t]{2}{*}{ Test } & \multirow[t]{2}{*}{$\mathrm{n}$} & \multicolumn{2}{|c|}{ Cortisol (pg/mL) } & \multicolumn{2}{|c|}{ Testosterone (pg/mL) } \\
\hline & & & Mean \pm SD & $(\%)$ & Mean \pm SD & $(\%)$ \\
\hline \multirow[t]{2}{*}{1} & Non gum & 12 & $898.28 \pm 531.15$ & $(100)$ & $46.44 \pm 16.31$ & (100) \\
\hline & gum & 12 & $899.01 \pm 421.53$ & (106.4) & $42.91 \pm 14.71$ & $(93.5)$ \\
\hline \multirow[t]{2}{*}{2} & Non gum & 12 & $1132.28 \pm 567.81$ & (100) & $46.85 \pm 18.34$ & (100) \\
\hline & gum & 12 & $948.77 \pm 442.39$ & $(85.2)$ & $48.9 \pm 20.49$ & (103.6) \\
\hline
\end{tabular}

over method. The results are shown in Table 2. There were no marked changes in the saliva $\mathrm{T}$ or $\mathrm{F}$ levels regardless of the presence or absence of stimulation.

Absolute ranges and diurnal changes in the blood and saliva levels of $T$ and $F$

The diurnal changes in the $\mathrm{T}$ and $\mathrm{F}$ levels in saliva samples from healthy males aged 20 to 65 years $(n=22)$ were evaluated with respect to age of sample. The saliva $\mathrm{T}$ level was highest at 6:00 (range 130 to $50 \mathrm{pg}$ / $\mathrm{mL})$, it was 40 to $90 \mathrm{pg} / \mathrm{mL}$ from 9:00 to 17:00, and decreased at 17:00 or later (30 to $60 \mathrm{pg} / \mathrm{mL}$ ) (Fig. 2a). The level of salivary $F$ was also the highest at 6:00 (range 2.5 to $3.5 \mathrm{ng} / \mathrm{mL}$ ) and gradually decreased to a minimum at 22:00 $(0.5 \mathrm{ng} / \mathrm{mL})$. The minimum corresponded to approximately $20 \%$ of the highest value, showing a marked diurnal change (Fig. 2b). The changes in the average values of both $\mathrm{T}$ and $\mathrm{F}$ levels in saliva samples from healthy males aged 20 to 65 years $(n=5)$ over 4 days are shown in Fig. 3; T showed a slight diurnal change in the evening and was stable in the morning.

Absolute ranges of total, bioavailable, and free $T$ and $F$ values in serum

The estimated absolute values of total, bioavailable, free, and saliva T were approximately 6000, 950, 70 , and $10 \mathrm{pg} / \mathrm{mL}$, respectively. The estimated absolute values of total, bioavailable, and saliva $\mathrm{F}$ were approximately 100,40 , and $3 \mathrm{pg} / \mathrm{mL}$, respectively. Therefore, the ratio of salivary/total $\mathrm{T}$ and $\mathrm{F}$ is $1.2 \%$ and $3.0 \%$, respectively, in this study. It should be considered that total, bioavailable, and free $\mathrm{T}$ in serum showed slight diurnal changes (Fig. 4a), while total and bioavailable $\mathrm{F}$ in serum showed marked diurnal changes (Fig. 4b).

\section{Relationship of the saliva $T$ and $F$ levels to age}

The relationship of the saliva $\mathrm{T}$ and $\mathrm{F}$ levels to age was evaluated. There was a negative correlation between the saliva $\mathrm{T}$ level and age regardless of the time of saliva collection $(\mathrm{r}=0.64, P<0.05)$ (Fig. 5a). However, there was no relationship between salivary $\mathrm{F}$ and age ( $r=0033, P>0.05$ ) (Fig. 5b).

\section{Discussion}

The presence of several steroid hormones in saliva has been reported previously [26]. However, as their levels are much lower than in blood, only some salivary hormones have been utilized in research. On the other hand, the use of saliva for hormone measurements facilitates sample collection and is a noninvasive, inexpensive procedure; thus, it may be very advantageous.

The measurement of T, F, and various steroid hormones is utilized in research fields such as sports medicine, clinical psychology, and pediatric clinic $[6,16$, 17, 21, 27]. However, values markedly differ among investigators. For example, Granger et al. reported the female saliva level of T ranged from 2 to $10 \mathrm{pg} /$ $\mathrm{mL}$ [27]; while, Kivlighan et al. indicated the level ranged from 100 to $250 \mathrm{pg} / \mathrm{mL}$ [28]. The difference was possibly due to limitations of the measurement method and sample management [29-31]. When saliva hormones are directly quantified using a kit designed for the measurement of blood hormones, values are increased due to the presence of a substance that inhibits the immune response in saliva [12]. As salivary $\mathrm{T}$ and $\mathrm{F}$ levels correspond to 1 to $5 \%$ of their serum level, direct quantification using a kit for measuring serum hormones is limited due to differences in detection sensitivity and matrix, compared to serum. These limitations need to be overcome to measure saliva hormones. 
fig. $2 a$

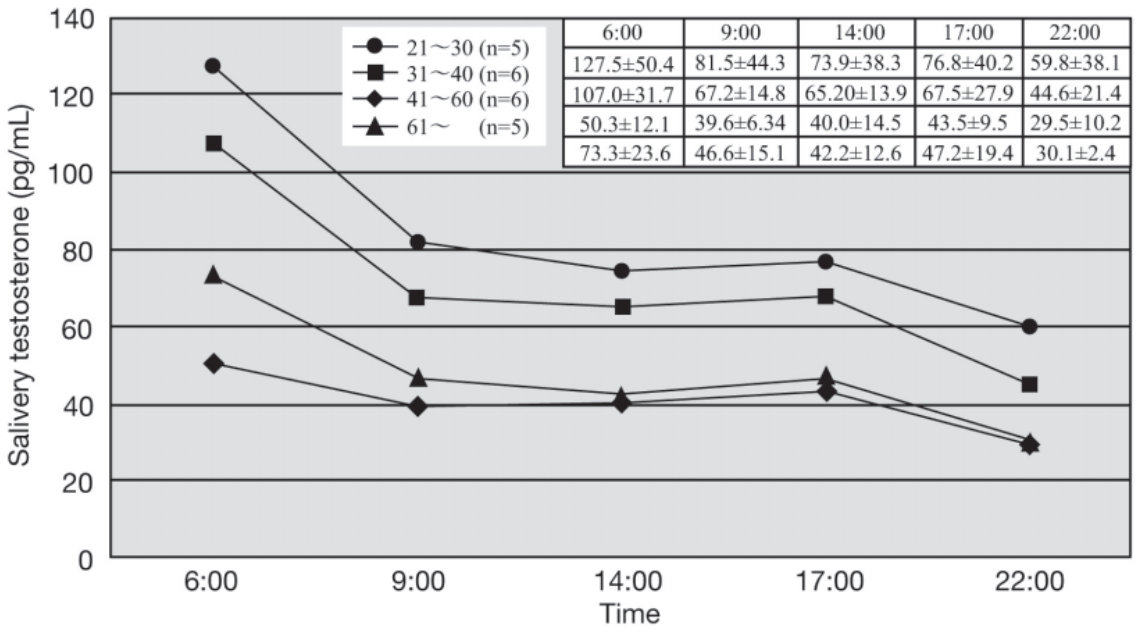

fig. $2 b$

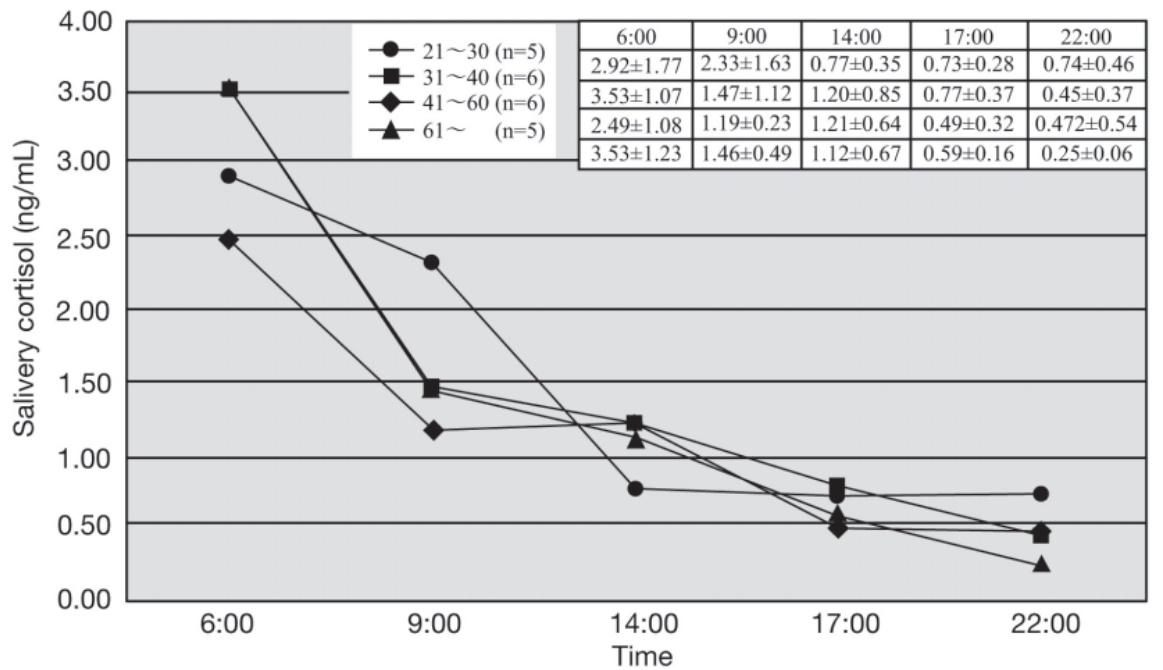

Fig. 2. The diurnal change of the average value in salivary (a) testosterone and (b) cortisol in each age group. The upper panels in the Fig show that the mean \pm SD (standard deviation) in each point.

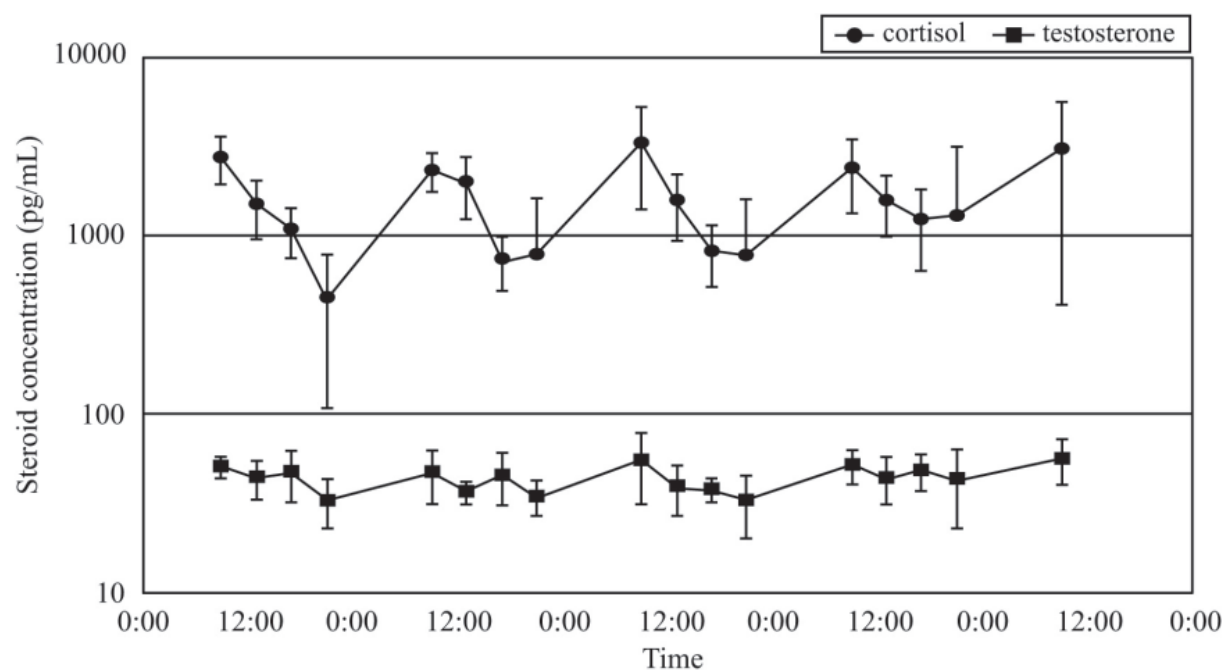

Fig. 3. The diurnal change of the average value of salivary testosterone and cortisol value over 4 days $(n=5)$. Bars indicate SD (standard deviation) in each point. 

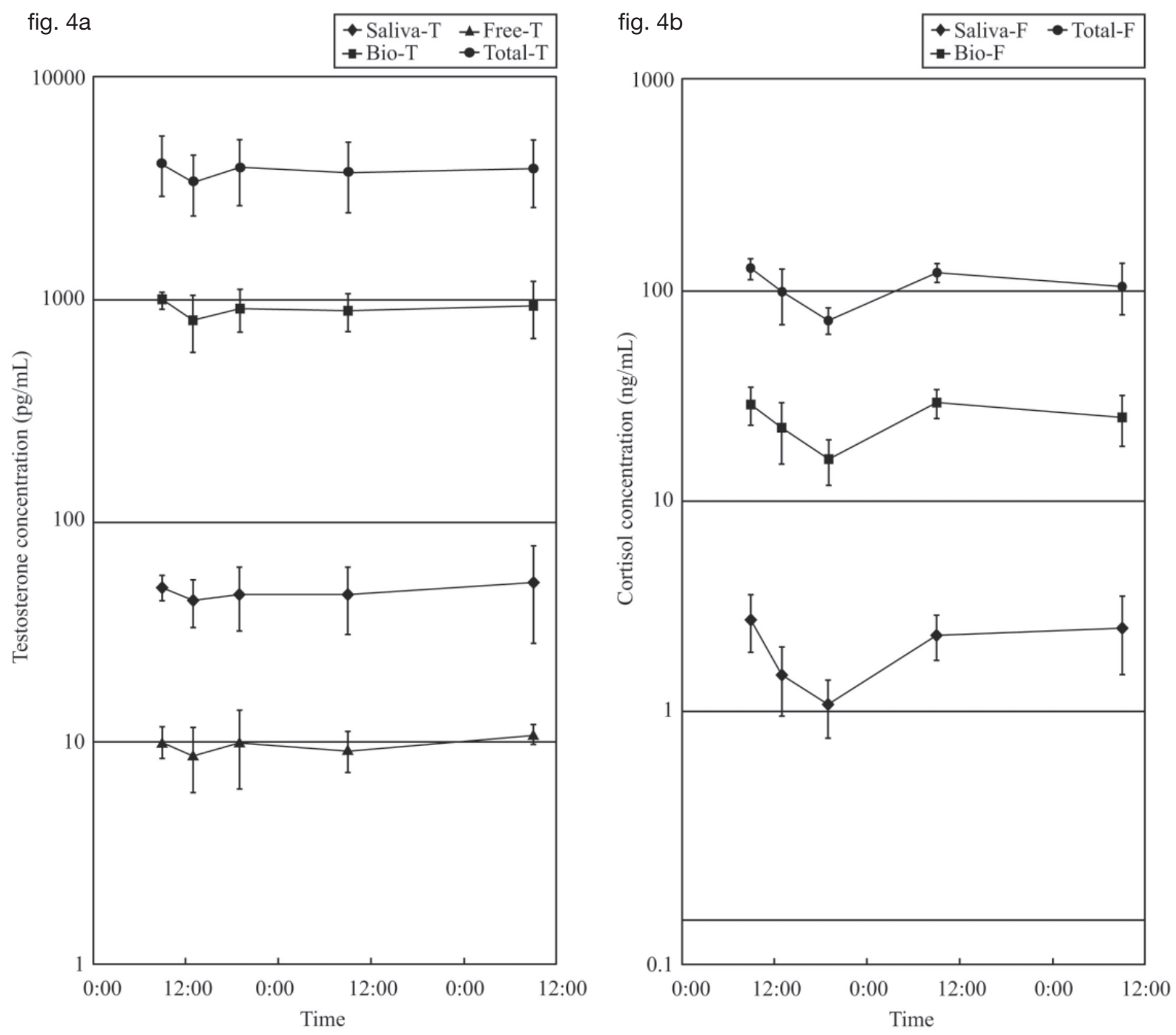

Fig. 4. The diurnal change of the average hormonal concentration.

(a) Salivary, bioavailable, free, and total testosterone and (b) saliva, bioavailable, and total cortisol are shown. Bars indicate SD (standard deviation) in each point.

We developed a method for simultaneous quantification of $\mathrm{T}$ and $\mathrm{F}$ in saliva using LC-MS/MS [9, 24], which has high specificity, sensitivity, and accuracy in the micro-quantification of steroid hormones. In the present study, the absolute range of saliva $\mathrm{T}$ was 50 to $130 \mathrm{pg} / \mathrm{mL}$ early in the morning and 40 to $90 \mathrm{pg} /$ $\mathrm{mL}$ during daytime. The absolute range of the saliva F was 2.5 to $3.5 \mathrm{ng} / \mathrm{mL}$ early in the morning, which gradually decreased to a minimum at late night $(0.5$ $\mathrm{ng} / \mathrm{mL}$ ). The ratio of salivary to total $\mathrm{T}$ and $\mathrm{F}$ is approximately $1.2 \%$ and $3.0 \%$, respectively, in healthy adult males.

In addition, we investigated the management of salivary samples on evaluated $\mathrm{T}$ and $\mathrm{F}$. There are reports demonstrating influences, such as dental care and sample management [30,31], have an effect on saliva hormone analysis. It is known that there are marked changes in hormone levels when the contamination from micro bleeding gums is present at the time of collection [28]. Therefore, saliva collection immediately after tooth brushing should be avoided.

A second limitation in saliva collection is adsorption to instruments. Saliva T level are $\sim 100 \mathrm{pg} / \mathrm{mL}$ or less and the steroid-binding protein levels are low; therefore, adsorption to instruments is a problem. When a linen rope is used for chimpanzee saliva collection, the rate of $\mathrm{F}$ adsorption is approximately $10 \%$ $[9,29]$. Furthermore, cotton used in a container for 
fig. $5 a$

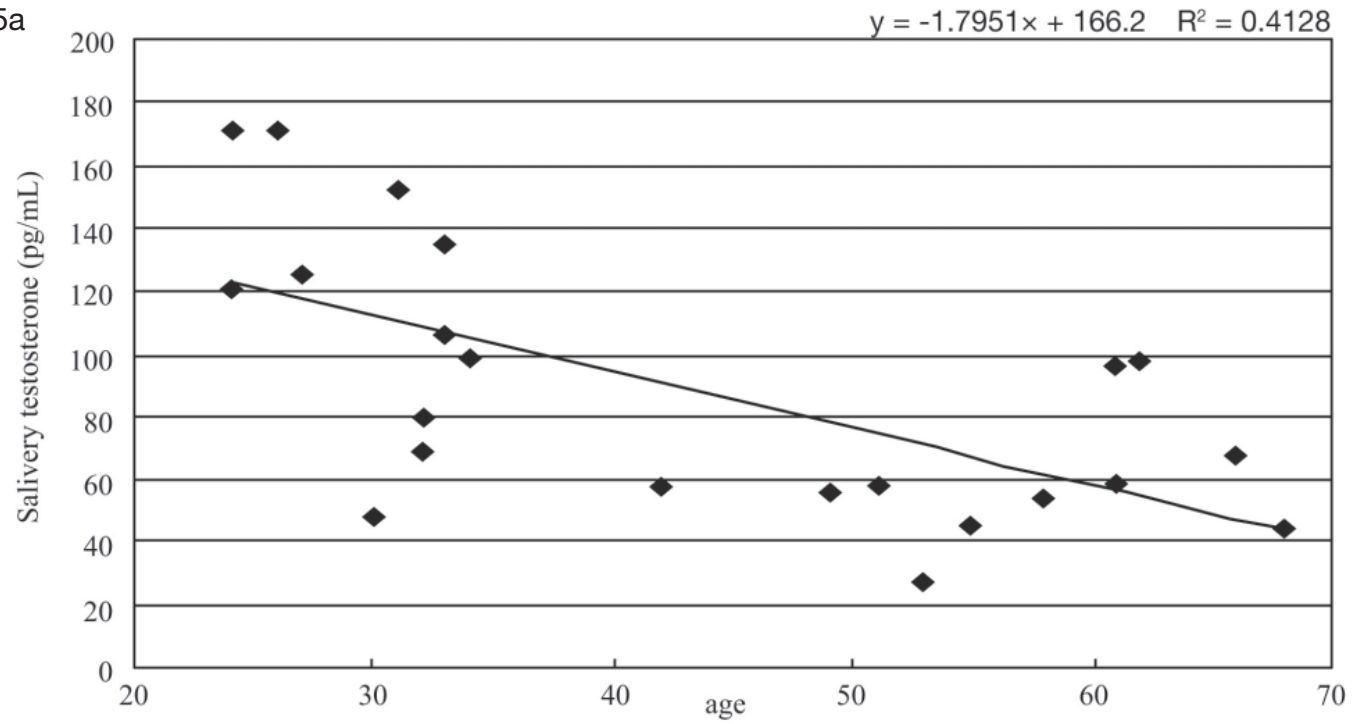

fig. $5 b$

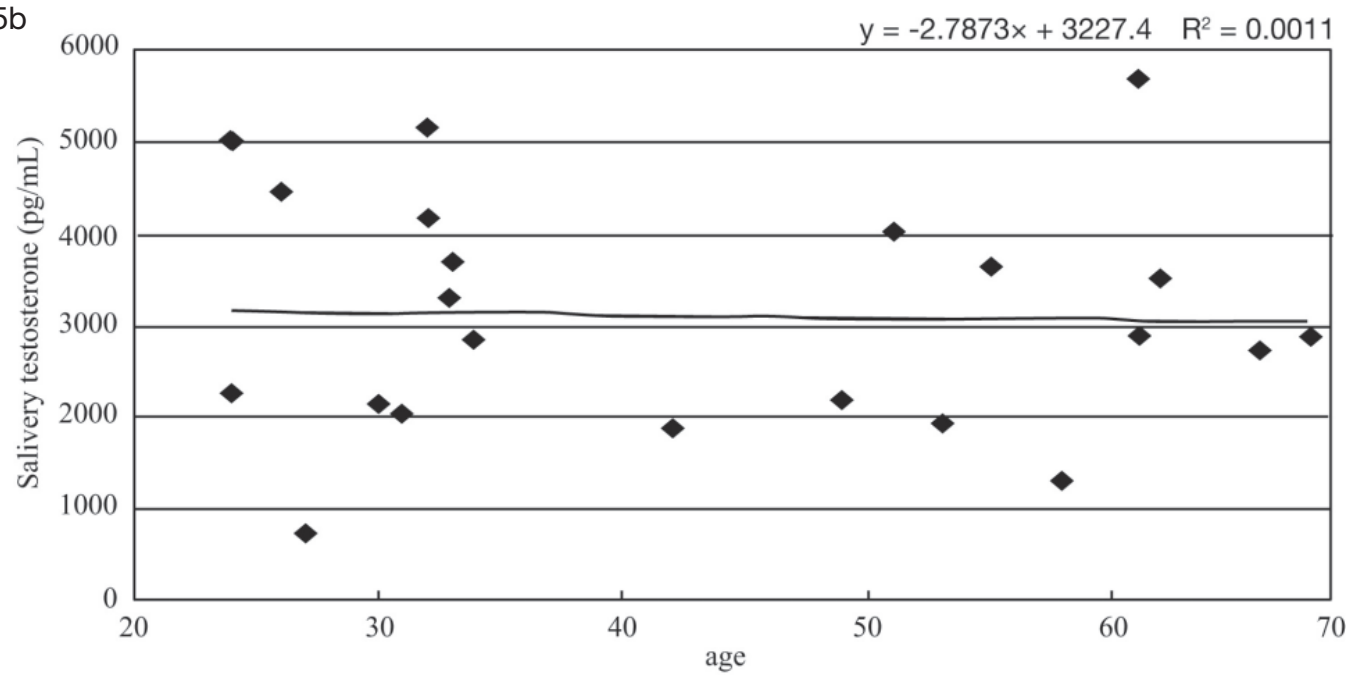

Fig. 5. The relationship of salivary (a) testosterone and (b) cortisol levels to age.

saliva collection (Salivette) contains several hormones and a relatively large amount of hormone is adsorbed to this cotton; therefore, values differ from those when saliva is collected directly [31]. The most reliable method is to collect saliva by direct spitting into a tube. If necessary, saliva secretion can be stimulated with gum chewing, as shown in Table 2.

The third important limitation is the management and storage of saliva samples. As shown in Fig. 1a.b, when saliva was placed at room temperature for 24 hours, the sample levels of $\mathrm{T}$ and $\mathrm{F}$ increased or decreased. However, the addition of an equivalent volume of ethanol to saliva reduced this change. When saliva was stored in a freezer, there were no marked changes. This suggests the involvement of steroidmetabolizing enzymes existing in saliva, especially $17 \beta$-hydroxysteroidodehydrogenase and $11 \beta$ hydroxysteroidodehydrogenase. The addition of $\mathrm{NNa} 3$ inhibited this enzymatic activity; however, it was not complete [29]. Saliva should be stored in a freezer immediately or with the addition of an equivalent volume of ethanol after collection. It is most convenient to store saliva in a refrigerator for 2 days or less (Fig. $1 \mathrm{a}, \mathrm{b}$ ).

Finally, diurnal changes in salivary $\mathrm{T}$ level are less marked than those of F. The former is high early in the morning, and does not change between 1:00 and 5:00 p.m. At 9:00 p.m., it slightly decreases. This pat- 
tern of change is similar to that in serum [27]. Salivary F shows marked diurnal changes, also demonstrated for blood F. Values determined between 6:00 a.m. and 9:00 p.m. differ markedly (5 to 7-fold). The pattern of diurnal change resembled that in blood. Thus, due to diurnal changes, $\mathrm{T}$ and $\mathrm{F}$ need to be collected at the same time each day to give meaningful results.

Many investigators recently reported salivary steroid hormones reflect serum free hormones [7, 32]. Saliva T reportedly correlates with age, differing from serum total $\mathrm{T}$, suggesting its usefulness in the diagnosis of $\mathrm{LOH}$ in males and genital insufficiency $[1,7,23]$. Salivary F was found to clearly correlate with serum bioavailable $\mathrm{F}$ [5]. As salivary $\mathrm{F}$ and $\mathrm{T}$ reflect serum active $\mathrm{F}$ and $\mathrm{T}$ (Fig. 4a, b), which have biological activity, they may be utilized for the diagnosis of endocrine diseases in clinical practice. Whether the hormone level in saliva is a good reflection of the serum hormone level, in cases of disorders, remains controversial.

Recent studies in clinical psychology involving stress and anxiety have examined salivary F, suggesting its usefulness $[2,6]$. The severity of depression is not associated with serum total F. However, its associ- ation with salivary $\mathrm{F}$ has been reported [33]. Aging is associated with an increased prevalence of mental and physical health problems. $\mathrm{LOH}$ in males can cause a variety of symptoms and the differential diagnosis includes psychological disorders, stress, and mood disturbances [33-36]. Saliva T diurnal variation vary according to the patients' psychological disorders [27]. Moreover, saliva hormones facilitate accurate evaluation of fine physiological changes, which can be detected by diurnal patterns and age-related declines in the serum hormone, because multiple specimens can be obtained from the same individual at the optimum times for evaluation of hormone status.

The accurate assessment of these hormone levels is of major clinical importance. If the differential diagnosis points to a strong possibility of a depression disorder, the patient preferentially should be treated for depression instead of androgen replacement therapy. Thus, LC-MS/MS not only allows rapid, simultaneous, sensitive, and accurate quantification of $\mathrm{T}$ and $\mathrm{F}$ in saliva for diagnosis $\mathrm{LOH}$ in male or psychological disorders, but is also applicable for monitoring $\mathrm{T}$ and F levels after replacement therapy.

\section{References}

1. Goncharov N, Katsya G, Dobracheva A, Nizhnik A, Kolesnikova G, Herbst V, Westermann J (2006) Diagnostic significance of free salivary testosterone measurement using a direct luminescence immunoassay in healthy men and in patients with disorders of androgenic status. Aging Male 9: 111-122.

2. Arafah BM, Nishiyama FJ, Tlaygeh H, Hejal R (2007) Measurement of salivary cortisol concentration in the assessment of adrenal function in critically ill subjects: a surrogate marker of the circulating free cortisol. $J$ Clin Endocrinol Metab 92: 2965-2971.

3. Hofman LF (2001) Human saliva as a diagnostic specimen. J Nutr 131: 1621S-1625S.

4. Cefalu WT, Pardridge WM, Chaudhuri G, Judd HL (1986) Serum bioavailability and tissue metabolism of testosterone and estradiol in rat salivary gland. J Clin Endocrinol Metab 63: 20-28.

5. Becker JB, Arnold AP, Berkley KJ, Blaustein JD, Eckel LA, Hampson E, Herman JP, Marts S, Sadee W, Steiner M, Taylor J, Young E (2005) Strategies and methods for research on sex differences in brain and behavior. Endocrinology 146: 1650-1673.

6. Lac G (2001) Saliva assays in clinical and research biology. Pathol Biol (Paris) 49: 660-667.
7. Morley JE, Perry HM, 3rd, Patrick P, Dollbaum CM, Kells JM (2006) Validation of salivary testosterone as a screening test for male hypogonadism. Aging Male 9: 165-169.

8. Brown GL, McGarvey EL, Shirtcliff EA, Keller A, Granger DA, Flavin K (2008) Salivary cortisol, dehydroepiandrosterone, and testosterone interrelationships in healthy young males: a pilot study with implications for studies of aggressive behavior. Psychiatry Res 159: 67-76.

9. Kutsukake N, Ikeda K, Honma S, Teramoto M, Mori Y, Hayasaka I, Yamamoto R, Ishida T, Yoshikawa Y, Hasegawa T (2009) Validation of salivary cortisol and testosterone assays in chimpanzees by liquid chromatography-tandem mass spectrometry. Am J Primatol 71: 696-706.

10. Stanczyk FZ (2006) Measurement of androgens in women. Semin Reprod Med 24: 78-85.

11. Gadea M, Gomez C, Gonzalez-Bono E, Salvador A, Espert R (2003) Salivary testosterone is related to both handedness and degree of linguistic lateralization in normal women. Psychoneuroendocrinology 28: 274-287.

12. Dabbs JM, Jr., Campbell BC, Gladue BA, Midgley AR, Navarro MA, Read GF, Susman EJ, Swinkels LM, 
Worthman CM (1995) Reliability of salivary testosterone measurements: a multicenter evaluation. Clin Chem 41: 1581-1584.

13. Taieb J, Mathian B, Millot F, Patricot MC, Mathieu E, Queyrel N, Lacroix I, Somma-Delpero C, Boudou P (2003) Testosterone measured by 10 immunoassays and by isotope-dilution gas chromatography-mass spectrometry in sera from 116 men, women, and children. Clin Chem 49: 1381-1395.

14. Nelson RE, Grebe SK, DJ OK, Singh RJ (2004) Liquid chromatography-tandem mass spectrometry assay for simultaneous measurement of estradiol and estrone in human plasma. Clin Chem 50: 373-384.

15. Higashi T (2006) Trace determination of steroids causing age-related diseases using LC/MS combined with detection-oriented derivatization. Chem Pharm Bull (Tokyo) 54: 1479-1485.

16. Elloumi M, Maso F, Michaux O, Robert A, Lac G (2003) Behaviour of saliva cortisol [C], testosterone [T] and the $\mathrm{T} / \mathrm{C}$ ratio during a rugby match and during the post-competition recovery days. Eur J Appl Physiol 90: 23-28.

17. Maso F, Lac G, Filaire E, Michaux O, Robert A (2004) Salivary testosterone and cortisol in rugby players: correlation with psychological overtraining items. $\mathrm{Br} \mathrm{J}$ Sports Med 38: 260-263.

18. Arregger AL, Contreras LN, Tumilasci OR, Aquilano DR, Cardoso EM (2007) Salivary testosterone: a reliable approach to the diagnosis of male hypogonadism. Clin Endocrinol (Oxf) 67: 656-662.

19. Carroll T, Raff H, Findling JW (2008) Late-night salivary cortisol measurement in the diagnosis of Cushing's syndrome. Nat Clin Pract Endocrinol Metab 4: 344-350.

20. Doi M, Sekizawa N, Tani Y, Tsuchiya K, Kouyama R, Tateno T, Izumiyama H, Yoshimoto T, Hirata Y (2008) Late-night salivary cortisol as a screening test for the diagnosis of Cushing's syndrome in Japan. Endocr $J$ 55: 121-126.

21. Suda M, Morimoto K, Obata A, Koizumi H, Maki A (2008) Emotional responses to music: towards scientific perspectives on music therapy. Neuroreport 19: 75-78.

22. Vining RF, McGinley RA, Maksvytis JJ, Ho KY (1983) Salivary cortisol: a better measure of adrenal cortical function than serum cortisol. Ann Clin Biochem 20 (Pt 6): 329-335.

23. Namiki M, Akaza H, Shimazui T, Ito N, Iwamoto T, Baba K, Kumano H, Koh E, Tsujimura A, Matsumiya K, Horie S, Maruyama O, Marumo K, Yanase T, Kumamoto Y (2008) Clinical practice manual for lateonset hypogonadism syndrome. Int J Urol 15: 377-388.

24. Shibayama Y, Higashi T, Shimada K, Odani A,
Mizokami A, Konaka H, Koh E, Namiki M (2008) Simultaneous determination of salivary testosterone and dehydroepiandrosterone using LC-MS/MS: Method development and evaluation of applicability for diagnosis and medication for late-onset hypogonadism. J Chromatogr B Analyt Technol Biomed Life Sci 877(25): 2615-23.

25. Yamamoto K, Koh E, Namiki M (2009) Measurementspecific bioavailable testosterone (BT) using concanavalin A precipitation.: Comparison of calculated and assayed BT Int J Urol 16(11): 894-901.

26. Dabbs JM, Jr. (1990) Salivary testosterone measurements: reliability across hours, days, and weeks. Physiol Behav 48: 83-86.

27. Granger DA, Shirtcliff EA, Zahn-Waxler C, Usher B, Klimes-Dougan B, Hastings P (2003) Salivary testosterone diurnal variation and psychopathology in adolescent males and females: individual differences and developmental effects. Dev Psychopathol 15: 431-449.

28. Kivlighan KT, Granger DA, Schwartz EB, Nelson V, Curran M, Shirtcliff EA (2004) Quantifying blood leakage into the oral mucosa and its effects on the measurement of cortisol, dehydroepiandrosterone, and testosterone in saliva. Horm Behav 46: 39-46.

29. Groschl M, Wagner R, Rauh M, Dorr HG (2001) Stability of salivary steroids: the influences of storage, food and dental care. Steroids 66: 737-741.

30. Whembolua GL, Granger DA, Singer S, Kivlighan KT, Marguin JA (2006) Bacteria in the oral mucosa and its effects on the measurement of cortisol, dehydroepiandrosterone, and testosterone in saliva. Horm Behav 49: 478-483.

31. Groschl M, Rauh M (2006) Influence of commercial collection devices for saliva on the reliability of salivary steroids analysis. Steroids 71: 1097-1100.

32. Sakaguchi K, Hasegawa T (2005) [Analysis of salivary testosterone by liquid chromatography-tandem mass spectrometry: correlation with serum bioavailable testosterone and aging]. Rinsho Byori 53: 388-394.

33. Young EA, Vazquez D, Jiang H, Pfeffer CR (2006) Saliva cortisol and response to dexamethasone in children of depressed parents. Biol Psychiatry 60: 831-836.

34. Barrett-Connor E, Von Muhlen DG, Kritz-Silverstein D (1999) Bioavailable testosterone and depressed mood in older men: the Rancho Bernardo Study. J Clin Endocrinol Metab 84: 573-577.

35. Tsujimura A, Matsumiya K, Matsuoka Y, Takahashi T, Koga M, Iwasa A, Takeyama M, Okuyama A (2003) Bioavailable testosterone with age and erectile dysfunction. J Urol 170: 2345-2347.

36. Booth A, Johnson DR, Granger DA (1999) Testosterone and men's depression: the role of social behavior. $J$ Health Soc Behav 40: 130-140. 